\title{
Genetic modifiers in carriers of repeat expansions in the C9ORF72 gene
}

Marka van Blitterswijk', Bianca Mullen ${ }^{1}$, Aleksandra Wojtas', Michael G Heckman², Nancy N Diehl², Matthew C Baker', Mariely DeJesus-Hernandez' ${ }^{1}$ Patricia H Brown', Melissa E Murray ${ }^{1}$, Ging-Yuek R Hsiung ${ }^{3}$, Heather Stewart ${ }^{3}$, Anna M Karydas ${ }^{4}$, Elizabeth Finger ${ }^{5}$, Andrew Kertesz ${ }^{5}$, Eileen H Bigio ${ }^{6}$, Sandra Weintraub ${ }^{6}$, Marsel Mesulam ${ }^{6}$, Kimmo J Hatanpaa ${ }^{7}$, Charles L White III, Manuela Neumann ${ }^{8}$, Michael J Strong ${ }^{9}$, Thomas G Beach $^{10}$, Zbigniew K Wszolek ${ }^{11}$, Carol Lippa ${ }^{12}$, Richard Caselli ${ }^{13}$, Leonard Petrucelli ${ }^{1}$, Keith A Josephs ${ }^{14}$, Joseph E Parisi ${ }^{14}$, David S Knopman ${ }^{14}$, Ronald C Petersen ${ }^{14}$, lan R Mackenzie ${ }^{15}$, William W Seeley ${ }^{4}$, Lea T Grinberg ${ }^{4}$, Bruce L Miller ${ }^{4}$, Kevin B Boylan ${ }^{11}$, Neill R Graff-Radford ${ }^{11}$, Bradley F Boeve ${ }^{14}$, Dennis W Dickson ${ }^{1}$ and Rosa Rademakers ${ }^{1 *}$

\begin{abstract}
Background: Hexanucleotide repeat expansions in chromosome 9 open reading frame 72 (C9ORF72) are causative for frontotemporal dementia (FTD) and motor neuron disease (MND). Substantial phenotypic heterogeneity has been described in patients with these expansions. We set out to identify genetic modifiers of disease risk, age at onset, and survival after onset that may contribute to this clinical variability.

Results: We examined a cohort of 330 C9ORF72 expansion carriers and 374 controls. In these individuals, we assessed variants previously implicated in FTD and/or MND; 36 variants were included in our analysis. After adjustment for multiple testing, our analysis revealed three variants significantly associated with age at onset (rs7018487 [UBAP1; $p$-value $=0.003]$, rs6052771 [PRNP; $p$-value $=0.003]$, and rs7403881 [MT-le; $p$-value $=0.003]$ ), and six variants significantly associated with survival after onset (rs5848 [GRN; p-value $=0.001]$, rs7403881 [MT-le; p-value $=0.001]$, rs13268953 [ELP3; $p$-value $=0.003]$, the epsilon 4 allele [APOE; $p$-value $=0.004]$, rs12608932 [UNC13A; p-value $=0.003]$, and rs1800435 $[A L A D ; p$-value $=0.003]$ ).

Conclusions: Variants identified through this study were previously reported to be involved in FTD and/or MND, but we are the first to describe their effects as potential disease modifiers in the presence of a clear pathogenic mutation (i.e. C9ORF72 repeat expansion). Although validation of our findings is necessary, these variants highlight the importance of protein degradation, antioxidant defense and RNA-processing pathways, and additionally, they are promising targets for the development of therapeutic strategies and prognostic tests.
\end{abstract}

Keywords: C9ORF72, Frontotemporal dementia, Motor neuron disease, Genetic modifier, Repeat expansion

\section{Background}

Two fatal neurodegenerative diseases, frontotemporal dementia (FTD) and motor neuron disease (MND), demonstrate clinical, pathological and genetic overlap. In up to $50 \%$ of FTD patients, for instance, signs of motor neuron dysfunction are present and an equal percentage of MND patients can show cognitive symptoms of

\footnotetext{
* Correspondence: Rademakers.Rosa@mayo.edu

'Department of Neuroscience, Mayo Clinic, 4500 San Pablo Road, Jacksonville, FL 32224, USA

Full list of author information is available at the end of the article
}

frontal lobe impairment [1-4]. Moreover, inclusions of transactive response DNA-binding protein 43 (TDP-43) are the most common subtype of FTD and are also a pathological hallmark of MND [5,6]. Interestingly, hexanucleotide repeat expansions in the chromosome 9 open reading frame 72 (C9ORF72) gene have been identified in FTD and MND [7,8], representing the most frequent genetic cause of both diseases [9]. Considerable clinical variability, however, has been detected in carriers of these expansions, including heterogeneity in age at onset and disease duration [10]. While recent 
studies implicated variants in transmembrane protein $106 \mathrm{~B}$ (TMEM106B), intermediate repeats in ataxin-2 (ATXN2), C9ORF72 expansion size, and the presence of double mutations as genetic modifiers of the clinical presentation in C9ORF72 expansion carriers [11-15], it remains largely unknown why some individuals develop disease symptoms in their 40s whereas others remain unaffected until old age.

In C9ORF72 expansion carriers, FTD and/or MNDassociated variants that modify disease risk, age at onset or survival after onset have not been studied systematically. For this reason, we conducted a thorough literature search and included 36 known variants in our study. These variants were investigated in a cohort of 330 C9ORF72 expansion carriers and 374 controls; importantly, we identified eight potential disease modifiers that may aid in explaining the reported phenotypic heterogeneity.

\section{Results}

We investigated a cohort of 330 C9ORF72 expansion carriers and 374 controls for 36 variants known to modify disease risk, age at onset or survival after onset in FTD and/or MND (Table 1; Additional file 1: Table S1). For simplicity, we have included an overview of significant associations, displaying only the genotypic model for which evidence of association was strongest (Table 2); results of all genotypic models for analyses that contained significant associations are shown in the supplement (Additional file 1: Table S2 [age at onset] and Additional file 1: Table S3 [survival after onset]).

Our primary analysis focused on the 265 probands carrying C9ORF72 repeat expansions with FTD, FTD/ MND, or MND. Under a false discovery rate (FDR) of $10 \%$, none of the variants studied was significantly associated with disease risk, neither in our overall group nor in any of our disease subgroups. Age at onset analysis, however, revealed three significant associations in our overall group (Table 2; Figure 1). Each additional minor allele of rs7018487 (ubiquitin-associated protein 1 [UBAP1]) was associated with a decrease in mean age at onset of 2.62 years $(\mathrm{p}$-value $=0.003$; additive genotypic model). For rs6052771 (prion protein $[P R N P]$ ), the mean age at onset was 4.42 years later in probands with two copies of the minor allele, than in probands with at least one copy of the major allele ( $p$-value $=0.003$; recessive genotypic model). Probands carrying at least one copy of the minor allele in rs7403881 (metallothionein $1 \mathrm{E}$ [MT-Ie] haploblock), demonstrated a delay of 3.95 years in mean age at onset as compared to probands homozygous for the major allele ( $\mathrm{p}$-value $=0.003$; dominant genotypic model). We did not detect significant associations for any of the disease subgroups.

In the 221 FTD, FTD/MND, and MND probands with information available regarding survival after onset, median follow-up length after onset was three years (range: 4 months -24 years [FTD: 1 year -24 years, FTD/MND: 10 months -24 years, MND: 4 months -9 years]). The survival after onset analysis resulted in significant associations with six variants (Table 2). Of those associations, one was present in our overall group, three were present in our FTD subgroup, and two were present in our MND subgroup. When concentrating on our overall group (Table 2; Figure 2), we noted a significant association only for rs5848 (granulin precursor [GRN]; relative risk $[R R]=1.64$; $\mathrm{p}$-value $=0.001$; additive genotypic model). However, we also performed an additional analysis to evaluate the combined effect of two other variants, rs13268953 and rs6985069 (elongator acetyltransferase complex subunit 3 [ELP3]; not in linkage disequilibrium [LD]), on survival after onset, especially because these variants both showed non-significant trends towards an association and were located near the same gene. When combining these variants, we did detect a significant association with survival after onset ( $\mathrm{p}$-value $=0.001$; Additional file 1: Table S4).

In our disease subgroups (Table 2; Figure 2), we observed significant associations in our FTD probands for rs7403881 (MT-Ie; $\mathrm{RR}=3.81 ; \quad \mathrm{p}$-value $=0.001 ;$ recessive genotypic model), rs13268953 (ELP3; $\mathrm{RR}=3.65$; $\mathrm{p}$-value $=0.003$; recessive genotypic model), and the epsilon 4 allele (apolipoprotein E $[A P O E]$; rs429358 and rs7412; RR = 3.13; p-value $=0.004$; dominant genotypic model). In our MND probands, significant associations were found for rs12608932 (unc-13 homolog $\mathrm{A}, \mathrm{C}$. elegans $[U N C 13 A]$; $\mathrm{RR}=5.65$; pvalue $=0.003$; recessive genotypic model) and rs1800435

\section{Table 1 Subject characteristics}

\begin{tabular}{|c|c|c|c|c|c|}
\hline Group & $\mathbf{N}$ & Female gender & Age & Age at onset & Pathological diagnosis \\
\hline Controls & 374 & $172(46.0 \%)$ & $61.2 \pm 10.2(35-90)$ & $N / A$ & $\mathrm{~N} / \mathrm{A}$ \\
\hline All repeat expansion carriers & 330 & $149(45.2 \%)$ & $59.4 \pm 10.0(35-90)$ & $56.5 \pm 9.1(34-83)$ & $123(37.3 \%)$ \\
\hline FTD, FTD/MND, and MND probands & 265 & $115(43.4 \%)$ & $59.6 \pm 10.0(35-90)$ & $56.8 \pm 9.1(34-83)$ & $112(42.3 \%)$ \\
\hline FTD probands & 74 & $29(39.2 \%)$ & $63.1 \pm 12.2(35-90)$ & $57.7 \pm 9.8(34-79)$ & $45(60.8 \%)$ \\
\hline FTD/MND probands & 71 & $25(35.2 \%)$ & $60.6 \pm 8.5(39-80)$ & $56.2 \pm 9.0(34-74)$ & $51(71.8 \%)$ \\
\hline MND probands & 120 & $61(50.8 \%)$ & $56.9 \pm 8.6(37-83)$ & $56.5 \pm 8.7(36-83)$ & $16(13.3 \%)$ \\
\hline
\end{tabular}

Continuous variables are summarized with the sample mean \pm standard deviation (range). The age provided is age at blood draw in controls, age at onset in clinically diagnosed patients, and age at death in pathologically diagnosed patients. Information was unavailable for age $(n=41)$ and age at onset $(n=59)$. 
Table 2 Variants significantly associated with age at onset or survival after onset

\begin{tabular}{|c|c|c|c|c|}
\hline Variant (gene/disease group) & Number of patients with each genotype ${ }^{a}$ & Model & Association measure $(95 \% \mathrm{Cl})$ & P-value \\
\hline \multicolumn{3}{|l|}{ Age at onset (overall) } & \multicolumn{2}{|l|}{ Regression coefficient } \\
\hline rs7018487 (UBAP1) & $122 / 96 / 23$ & Additive & $-2.62(-4.36,-0.89)$ & 0.003 \\
\hline rs6052771 (PRNP) & 92 / 104 / 46 & Recessive & $4.42(1.51,7.32)$ & 0.003 \\
\hline rs7403881 (MT-le) & $65 / 118 / 60$ & Dominant & $3.95(1.36,6.54)$ & 0.003 \\
\hline \multicolumn{3}{|l|}{ Survival after onset (overall) } & \multicolumn{2}{|l|}{ Relative risk } \\
\hline rs5848 (GRM) & $116 / 86 / 19$ & Additive & $1.64(1.22,2.22)$ & 0.001 \\
\hline \multicolumn{3}{|c|}{ Survival after onset (disease subgroups) } & \multicolumn{2}{|l|}{ Relative risk } \\
\hline rs7403881 (MT-le): FTD & $13 / 31 / 14$ & Recessive $^{b}$ & $3.81(1.71,8.46)$ & 0.001 \\
\hline rs13268953 (ELP3): FTD & $16 / 31 / 11$ & Recessive & $3.65(1.56,8.55)$ & 0.003 \\
\hline Epsilon 4 (APOE): FTD & $42 / 13 / 2$ & Dominant & $3.13(1.45,6.74)$ & 0.004 \\
\hline rs12608932 (UNC13A): MND & $44 / 40 / 23$ & Recessive $^{b}$ & $5.65(1.82,17.58)$ & 0.003 \\
\hline rs1800435 (ALAD): MND & $88 / 18 / 1$ & Dominant & $N / A^{c}$ & 0.003 \\
\hline
\end{tabular}

Association measure $=$ regression coefficient (age at onset analysis) and relative risk (survival after onset analysis); $\mathrm{Cl}=\mathrm{confidence} \mathrm{interval}$. Additive models, dominant models, and recessive models were utilized. We adjusted for multiple testing using a false discovery rate (FDR) of 10\%. ${ }^{\mathrm{a} O r d e r}$ of genotypes: major-major/major-minor/ minor-minor. ' Indicates that the variant was also significantly associated with the given outcome under an additive model. 'For rs 1800435 , none of the 19 MND patients $(0.0 \%)$ who carried the minor allele died as compared to 14 of 78 MND patients (15.9\%) who did not carry the minor allele; the p-value of 0.003 results from a log-rank test. The strongest association with the given outcome is displayed in this table; other associations are shown in Additional file 1: Table S2 (age at onset) and Additional file 1: Table S3 (survival after onset).

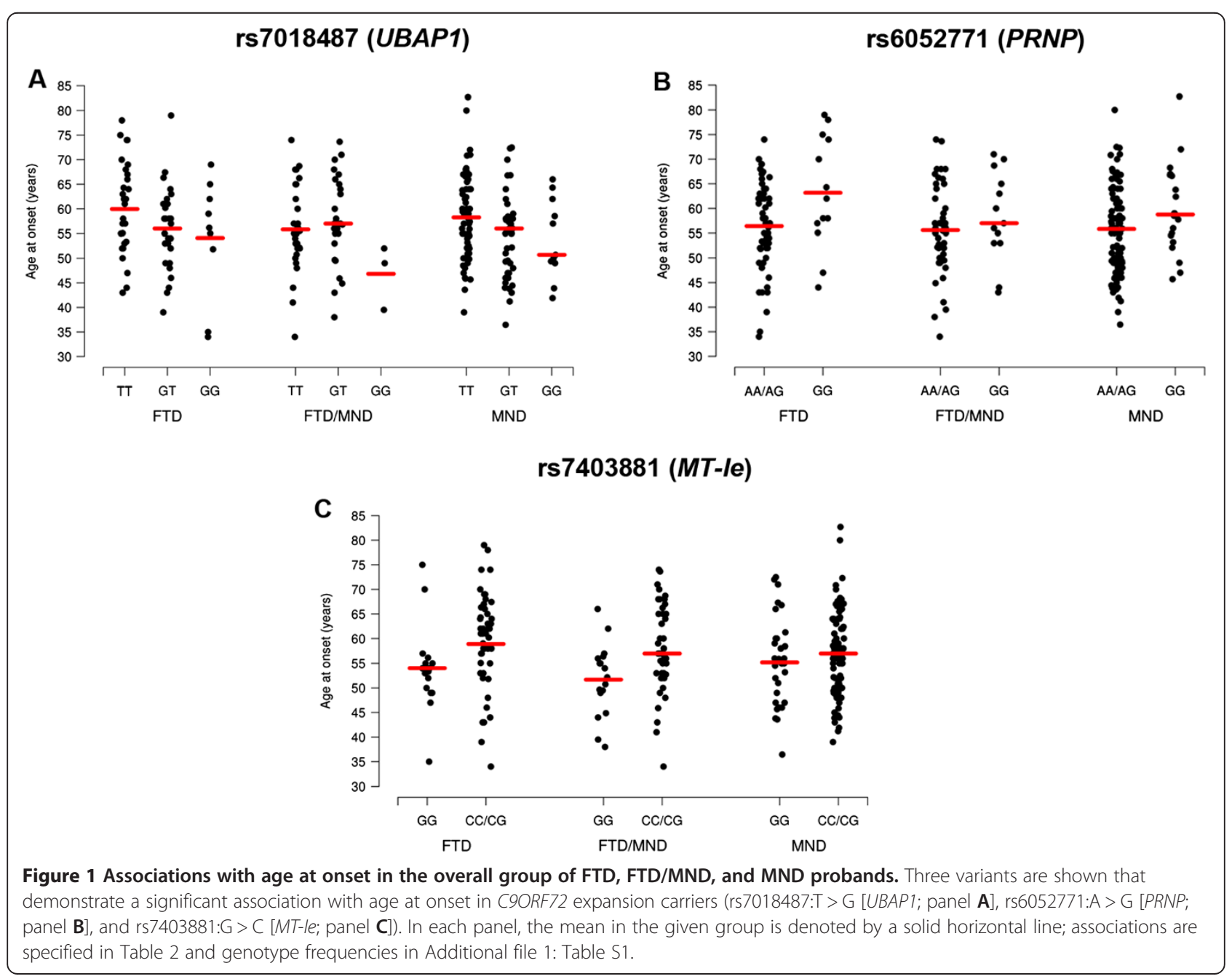




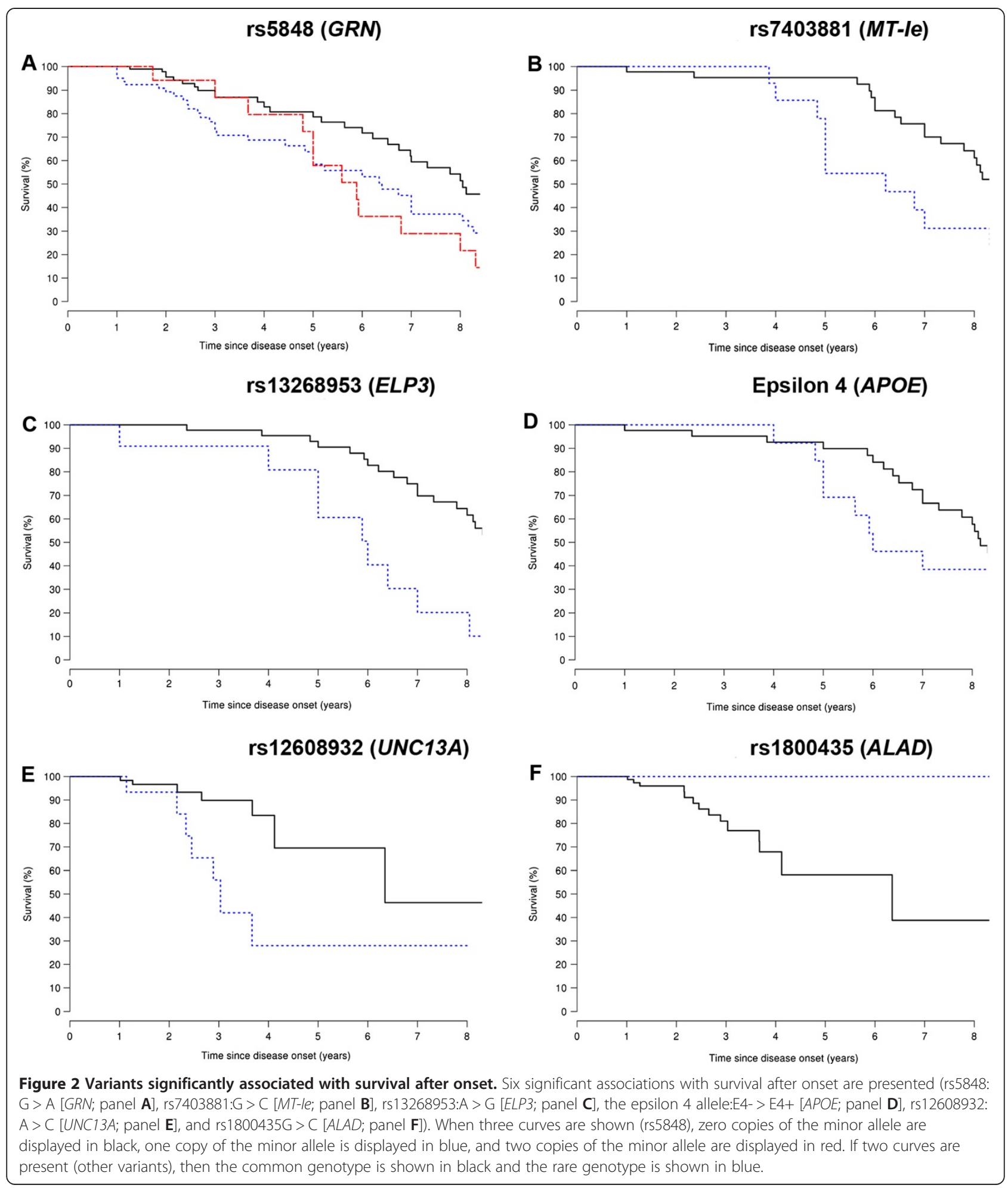


(delta-aminolevulinate dehydratase $[A L A D] ; 0.0 \%$ death in carriers of minor allele versus $15.9 \%$ in non-carriers; $\mathrm{p}$-value $=0.003$; dominant genotypic model).

Of note, all results of statistical analyses involving disease risk, age at onset and survival after onset were very similar when including individuals who were family members or who had received another diagnosis, and also when additionally adjusting models for age in the disease risk analysis (data not shown).

\section{Discussion}

This study was designed to help elucidate the clinical variability observed in C9ORF72 expansion carriers. We investigated variants previously implicated in FTD and/or MND, and determined their effects in a unique cohort of subjects with known pathogenic expansions in C9ORF72. Excitingly, we discovered eight variants that may assist in explaining the reported phenotypic variability, especially with regard to age at onset and survival after onset (Table 2). Although it should be stressed that replication is needed, our results represent a major step forward in the search for genetic modifiers, and they provide directions for future validation and meta-analytical studies.

We identified one single nucleotide polymorphism (SNP) located near UBAP1 (rs7018487) that was associated with age at onset in our overall group of C9ORF72 expansion carriers ( $p$-value $=0.003)$. UBAP1 functions in ubiquitin-dependent sorting at the multivesicular body (MVB), and depletion of UBAP1 severely disrupts this complex process $[16,17]$. Variants in $U B A P 1$ have already been linked to FTD risk, and colocalization of UBAP1 and TDP-43 in neuronal cytoplasmic inclusions has been demonstrated [18]. Our results also revealed an association between PRNP (rs6052771; in LD with rs1799990) and age at onset in our overall group ( $p$-value $=0.003$ ). The contribution of PRNP to the pathogenesis of FTD and/or MND has not been studied thoroughly $[19,20]$, and consequently, little is known about its effects on these diseases. One study, however, reported an association of $P R N P$ with age at onset in a small number of FTD patients harboring GRN mutations [21], supporting the premise of a common underlying mechanism.

Moreover, we discovered a variant in metallothionein (rs7403881) that is associated with a delayed age at onset in our overall group ( $p$-value $=0.003$ ). In addition to this delay, we detected a decrease in survival after onset in our FTD subgroup ( $p$-value $=0.001$ ). Currently, only a few studies investigating FTD and/or MND have focused on the metallothionein family, which is involved in antioxidant defense [22]. One of these studies suggested that rs7403881 increases MND risk [23]. A recent study in superoxide dismutase-1 (Sod1) mice, revealed that overexpression of metallothioneins slows disease progression and extends lifespan [24]. Further evidence for a potential role of oxidative stress is provided by the association between survival after onset and a coding SNP in ALAD (rs1800435; p-value $=0.003$ ). The ALAD enzyme influences susceptibility to lead exposure, which may contribute to MND risk; although studies published thus far are insufficient for a definitive conclusion [25-27].

Interestingly, we also found a significant association between a functional SNP in GRN (rs5848; 3'-untranslated region [UTR]) and survival after onset in our overall group. It has already been reported that carriers homozygous for the minor allele of rs5848 demonstrate an increased FTD risk as compared to homozygous major allele carriers [28], but no associations with either FTD risk or age at onset were observed in other studies [21,29-32]. Thus, although the contribution of GRN SNPs to neurodegenerative diseases has not been elucidated, our present finding suggests that GRN is associated with survival after onset in carriers of C9ORF72 repeat expansions ( $\mathrm{p}$-value $=0.001$ ).

We also examined two variants near ELP3 (rs13268953 and rs6985069; not in LD). ELP3 is a component of the RNA polymerase II complex, and as such, is involved in the acetylation of histones $\mathrm{H} 3$ and $\mathrm{H} 4$ to make DNA accessible for transcription [33,34]. Importantly, another type of histone modification has already been implicated in C9ORF72 expansion carriers: a recent report demonstrated that trimethylation of lysine residues within histones $\mathrm{H} 3$ and $\mathrm{H} 4$ might reduce $\mathrm{C} 9 \mathrm{ORF72}$ expression in expansion carriers [35]. An association study and mutagenesis screen have also exposed associations between ELP3 and MND susceptibility [36], representing one of many FTD and/or MND-associated genes that function in RNA-processing pathways [37]. Our present findings are in agreement with these studies, as shown by the combined effects of these ELP3 SNPs in our overall group (p-value $=0.001$ ), and one ELP3 SNP (rs13268953) in our FTD subgroup (p-value $=0.003$ ).

In addition, we assessed $A P O E$, a gene that has been carefully investigated, particularly in patients with dementia. A recent meta-analysis included 28 case-control studies, and demonstrated that the epsilon 4 allele increases susceptibility to FTD [38]. Interestingly, we discovered that the APOE epsilon 4 allele was associated with a decline in survival after onset in our FTD subgroup ( $\mathrm{p}$-value $=0.004)$.

Our last potential modifier (rs12608932), an intronic SNP in $U N C 13 A$, has been identified through a genomewide association study in MND patients [39]. This finding was strengthened by an analysis of expression quantitative trait loci (eQTLs) that demonstrated genome-wide significance for UNC13A [40]. UNC13A is involved in neurotransmitter release [41], a tightly regulated process that is thought to be disrupted in MND patients. Our results show that variants in UNC13A are also associated with survival after onset in the presence of a C9ORF72 repeat 
expansion: we detected an association in our MND subgroup ( $\mathrm{p}$-value $=0.003)$

We would like to reiterate that we performed a systematic study of variants reported in the literature. For many variants, however, previous findings were inconclusive and based on our current discoveries we speculate that some of the seemingly conflicting results are due to differences in the composition (and size) of study cohorts, most importantly: (1) the number of patients with predominant FTD, predominant MND or a mixture of both diseases, (2) the percentage of subjects with a pathologically confirmed diagnosis, and (3) the subset of individuals with pathogenic mutations in particular FTD and/or MNDassociated genes (such as C9ORF72). Hence, because of our present findings and results of aforementioned studies, reinvestigation of previously published data after exclusion of certain subgroups seems warranted, and new well-sized studies should be performed concentrating on these subgroups, in order to determine the specificity of results.

In our study, we used an FDR rather than a familywise error rate (FWER)-controlling procedure for multiple testing adjustments. The FDR procedure is relatively new, and controlling the FDR is a valid method to adjust for multiple comparisons [42]. An FDR correction, however, is less conservative than an FWER correction and its interpretation is different (Methods). We used an FDR of $10 \%$, which means that for each group of statistically significant associations we would expect the vast majority $(90 \%)$ to be real (i.e. for each group only 1 out of 10 significant findings is expected to be false). Naturally, there is always a balance between the two different types of statistical error that can occur for any given conclusion - a type I error (i.e. a false-positive association) and a type II error (i.e. a false-negative association), both of which are undesirable. Because the balance tips more in the direction of type I error for the FDR than for the FWER procedures, it is important to highlight that our results, though promising, do require validation.

Additionally, it should be noted that we focused our article on those associations that remained significant after adjustment for multiple testing. Future studies could investigate nominally significant associations (Additional file 1: Table S2 and Additional file 1: Table S3) in larger cohorts and/or meta-analyses, to determine whether any of these potential associations contribute to the pleiotropy detected in C9ORF72 expansion carriers. Other studies could also concentrate on variants not included in our present study (i.e. recently published variants); especially since it seems plausible that more variants (either known or unknown) modify the phenotype of C9ORF72 expansion carriers. Furthermore, our study was designed to investigate associations with disease risk (i.e. by comparing patients and controls) and to identify factors that could modify age at onset or survival after onset. Interestingly, some of the associations we observed were only significant in the phenotypic subgroup for which the risk variant was originally reported; for example, $A P O E$ genotypes only affected survival after onset in our subgroup of C9ORF72 expansion carriers with FTD, whereas the $U N C 13 A$ variant only affected survival after onset in our MND subgroup. To further investigate the clinical phenotype, a larger number of expansion carriers with either FTD or MND is needed (e.g. international genome-wide association study), so that direct comparisons of expansion carriers with FTD and MND could be performed.

\section{Conclusions}

Our present study reveals eight variants that may account for the phenotypic variability reported in C9ORF72 expansion carriers. These variants strongly emphasize the importance of proper protein degradation, antioxidant defense, and processing of RNA. Although identified genes (and their corresponding pathways) have already been linked to FTD and/or MND, it was unclear whether they were able to act as disease modifiers on the background of a C9ORF72 repeat expansion. Our findings, thus, underscore the complex interplay between many factors that influence the occurrence and prognosis of these destructive diseases, particularly in C9ORF72 expansion carriers. Though large for a study of C9ORF72 expansion carriers, our findings result from a relatively small sample size, and therefore, repeated replication and meta-analyses will be necessary to increase our understanding of these potential genetic disease modifiers. With that said, the factors identified in this study may represent excellent targets for novel treatments, including preventative treatment strategies, and for the development of predictive tests aiming at the continuum of FTD and MND.

\section{Methods}

\section{Subjects}

We collected DNA from a cohort of 330 C9ORF72 expansion carriers, obtained at the Mayo Clinic $(\mathrm{n}=121)$, Coriell Research Institute $(n=71)$, University of British Columbia, Canada $(\mathrm{n}=58)$, University of California, San Francisco $(\mathrm{n}=38)$, Robarts Research Institute $(\mathrm{n}=$ 11), Northwestern University Feinberg School of Medicine $(n=9)$, Drexel University College of Medicine $(n=7)$, University of Western Ontario, Canada $(n=7)$, Banner Sun Health Research Institute $(\mathrm{n}=5)$, and University of Tübingen $(\mathrm{n}=3)$. Based on available clinical and/or pathological data, these subjects were diagnosed with FTD $(\mathrm{n}=91)$, FTD/MND $(\mathrm{n}=78)$ or MND $(\mathrm{n}=127)$, with another diagnosis $(n=7$; e.g. dementia due to Alzheimer's disease, alcohol abuse or behavioral impairment), or they 
were asymptomatic at time of last evaluation $(n=27$; mean age at evaluation: $43.6 \pm 12.7$ standard deviation [SD]). Of those expansion carriers $45.2 \%(n=149)$ were female, their mean age was $59.4 \pm 10.0$ years, their main age at onset was $56.5 \pm 9.1$ years, and $37.3 \%(n=123)$ had received a neuropathological diagnosis (Table 1). Age at onset was estimated based on the appearance of the first disease symptoms, namely progressive cognitive dysfunction in judgment, language, or memory; or changes in behavior or personality (FTD patients); or fasciculations, muscle weakness, falls, dysarthria, and dysphagia (MND patients). When symptoms of both FTD and MND were noted, the earliest observation of decline was recorded for age at onset. Survival after onset was defined as the interval between age at onset of disease symptoms and the age at death for deceased patients, and as the interval between age at onset and present age for other patients (when follow-up data was available).

We also included neurologically normal controls $(\mathrm{n}=$ $374)$, of whom $46.0 \%(n=172)$ were female, and whose mean age was $61.2 \pm 10.2$ years. All subjects agreed to be in the study, and biological samples were obtained after informed consent with ethical committee approval from the respective institutions. Approval for the genetic analyses was performed in agreement with ethical committee approval at Mayo Clinic

\section{Genotyping}

C9ORF72 expansion carriers were identified using our previously published 2-step PCR protocol [7]; Southern blotting techniques were employed to confirm the presence of the repeat expansion when sufficient high quality DNA was available ( $>25 \%$ of expansion carriers) [14]. To select candidates that could potentially act as disease modifiers in carriers of C9ORF72 repeat expansions, we performed a literature search on PubMed (August 2012) that revealed all publications on a combination of FTD and/or MND with SNPs. Subsequently, we selected one or two variants per gene possibly associated with these diseases (top SNPs were preferred), which were suitable for the Sequenom MassArray iPLEX platform (San Diego, CA, USA) and could be incorporated in Sequenom panels; these variants were analyzed with Typer 4.0 software. Sequenom genotype data was supplemented with five Taqman SNP genotyping assays (C_3084793_20, C_108560 0_10, C_2070266_20, C_8921964_20, and C_7563736_10; Invitrogen, Carlsbad, CA, USA) performed on a 7900HT Fast Real Time PCR system; genotype calls were made using SDS 2.4 software (Applied Biosystems, Foster City, CA, USA). After genotyping, we excluded SNPs with a significant deviation from the Hardy-Weinberg equilibrium (HWE) in our control cohort (rs45559331 and rs6903982), rare SNPs with a minor allele frequency (MAF) of less than 1\% in expansion carriers and controls (rs121909536, rs75654767, rs121909541, rs140547520, rs80265967, rs80356715, and rs35070491), and SNPs with a call rate below 95\% (rs4680, rs4859146, rs854560, rs7277748, rs4880, and rs2275294). In total, 36 variants were included in our analysis (Additional file 1: Table S1); the call rate of these variants was greater than $99 \%$ and none of these variants was in LD. All genetic analyses were performed at the Mayo Clinic, and genotypes were assigned using all of the data from the study simultaneously.

\section{Statistical analysis}

In order to satisfy the statistical assumption of independent measurements, our primary analysis focused on a subset of C9ORF72 expansion carriers: 265 unrelated probands with FTD $(n=74)$, FTD/MND $(n=71)$, or MND $(n=120)$. We performed secondary analyses, however, that included the remaining expansion carriers to examine the sensitivity of our results. The entire cohort of C9ORF72 expansion carriers was assessed, and also disease subgroups separately (FTD, FTD/MND and MND). First, we used logistic regression models adjusted for gender to evaluate associations of each of the 36 variants with disease risk; odds ratios (ORs) and 95\% confidence intervals (CIs) were estimated. In addition, we examined associations of each of these variants with age at onset using linear regression models adjusted for gender and disease subgroup; while associations with survival after onset were assessed using Cox proportional hazards regression models adjusted for age at onset, gender, and disease subgroup. Regression coefficients (interpreted as changes in mean age at onset) and 95\% CIs were estimated in the age at onset linear regression analysis; whereas in Cox regression analysis, RRs and 95\% CIs were estimated, and data was censored at last follow-up. Each variant was investigated under an additive genotypic model (effect of each additional minor allele), a dominant genotypic model (presence versus absence of the minor allele), and a recessive genotypic model (presence versus absence of two copies of the minor allele). Models were not adjusted for C9ORF72 expansion size, since expansion sizes were only available for a subset of samples $(>25 \%)$ and they were estimated in DNA obtained from various tissues, which hampers analyses [14]. In order to reduce the chance of spurious findings and non-informative tests, association analyses were not performed for variants with fewer than ten carriers of the minor allele in the given group, or under an additive or recessive genotypic model when fewer than ten rare homozygotes were present in the given group.

To account for multiple testing, we made an adjustment separately for each disease group and separately for each outcome measure (disease risk, age at onset, and survival after onset). Given the relatively small sample size of this study, controlling the FWER (i.e. the 
probability of any false-positive finding among the entire group of tests) at $5 \%$ using a procedure such as a singlestep minP permutation correction [43] would result in very low power to detect associations. We, therefore, opted for an alternative approach and utilized an FDR correction [44]. This increasingly used method has a different interpretation than FWER-controlling procedures; an FDR procedure attempts to control the expected proportion of false-positive findings among those associations considered significant. Note that due to this difference in interpretation, the FDR does not necessarily need to be controlled at $5 \%$, only at a reasonable level to allow for high confidence in results, which was deemed at $10 \%$ for our study [42]. All statistical tests were two-sided, and were performed using SAS (version 9.2; SAS Institute, Inc., Cary, NC, USA) and R Statistical Software (version 2.14.0; R Foundation for Statistical Computing, Vienna, Austria).

\section{Additional file}

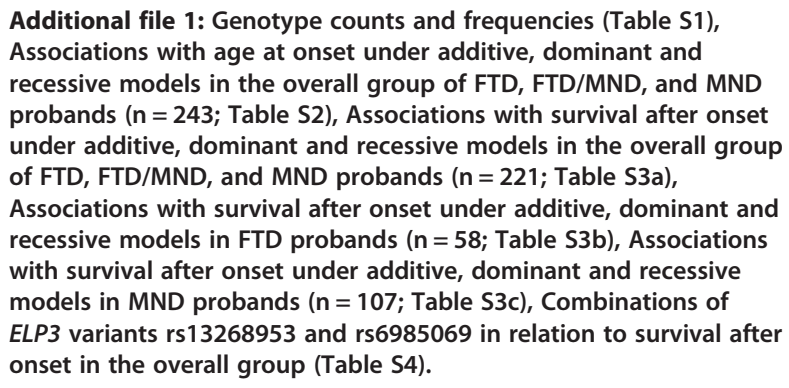

\section{Abbreviations}

FTD: Frontotemporal dementia; MND: Motor neuron disease;

TDP-43: transactive response DNA-binding protein 43;

C9ORF72: Chromosome 9 open reading frame 72;

TMEM106B: Transmembrane protein 106 B; ATXN2: Ataxin-2; FDR: False

discovery rate; UBAP1: Ubiquitin-associated protein 1; PRNP: Prion protein;

MT-le: Metallothionein $1 \mathrm{E}$; GRN: Granulin precursor; RR: Relative risk;

ELP3: Elongator acetyltransferase complex subunit 3; LD: Linkage disequilibrium; APOE: Apolipoprotein E; UNC13A: unc-13 homolog A, C. elegans; ALAD: Delta-aminolevulinate dehydratase; SNP: Single nucleotide polymorphism; MVB: Multivesicular body; Sod1: Superoxide dismutase-1; UTR: Untranslated region; eQTLs: Expression quantitative trait loci; FWER: Family-wise error rate; SD: Standard deviation; HWE: HardyWeinberg equilibrium; MAF: Minor allele frequency; OR: Odds ratio; $\mathrm{Cl}$ : Confidence interval.

\section{Competing interests}

Mariely DeJesus-Hernandez and Rosa Rademakers hold a patent on methods to screen for the hexanucleotide repeat expansion in the C9ORF72 gene. None of the other authors declares that they have competing interests.

\section{Authors' contributions}

MvB participated in the study concept and design, carried out molecular genetic studies, interpreted data, and additonally, drafted and revised the manuscript. BM, AW, MCB, MD-H, PHB, and MEM made substantial contributions to the acquisition of data, and the analysis or interpretation of data. MGH and NND performed statistical analyses and revised the manuscript. G-YRH, HS, AMK, EF, AK, EHB, SW, MM, KJH, CLWIII, MN, MJS, TGB, ZKW, CL, RC, LP, KAJ, JEP, DSK, WWS, and LTG contributed vital reagents/ tools/patients and revised the manuscript. RCP, IRM, BLM, KBB, NRG-R, $B F B$, and DWD obtained study funding, contributed vital reagents/tools/ patients, and revised the manuscript. RR obtained study funding and also supervised the study concept and design, acquisition of data, interpretation of data, and drafting as well as revision of the manuscript. All authors read and approved the final manuscript.

\section{Acknowledgements}

This work was supported by NIH grants R01 NS080882, R01 NS065782, R01 NS076471, R01 AG026251, P01 AG017586, P50 NS072187, P50 AG016574, P30 AG013854, P30 AG012300, P30 AG019610, U01 AG006786, the ALS Therapy Alliance, and the Consortium for Frontotemporal Dementia Research. Data collection at University of British Columbia is supported by CIHR grant \#179009. Dr. Van Blitterswijk is supported by the Milton Safenowitz Post-Doctoral Fellowship for ALS research from the ALS Association.

\section{Author details}

${ }^{1}$ Department of Neuroscience, Mayo Clinic, 4500 San Pablo Road, Jacksonville, FL 32224, USA. 'Section of Biostatistics, Mayo Clinic, 4500 San Pablo Road, Jacksonville, FL 32224, USA. ${ }^{3}$ Division of Neurology, University of British Columbia, 2211 Wesbrook Mall, Vancouver, BC V6T 2B5, Canada. ${ }^{4}$ Department of Neurology, University of California, 500 Parnassus Ave, San Francisco, CA 94143, USA. ${ }^{5}$ The University of Western Ontario, 1151 Richmond St, London, ON N6A 3 K7, Canada. ${ }^{6}$ Cognitive Neurology and Alzheimer's Disease Center, Northwestern University Feinberg School of Medicine, 320 East Superior Street, Chicago, IL 60611, USA. ${ }^{\text {University of }}$ Texas Southwestern Medical Center, 5323 Harry Hines Blvd., Dallas, TX 75390, USA. ${ }^{8}$ Department of Neuropathology, University of Tübingen and German Center for Neurodegenerative Diseases, Calwerstr. 3, Tübingen 72076, Germany. ${ }^{9}$ Molecular Brain Research Group, Robarts Research Institute, 100 Perth Drive, London, ON N6A 5 K8, Canada. ${ }^{10}$ Banner Sun Health Research Institute, 10515 W Santa Fe Dr, Sun City, AZ 85351, USA. ${ }^{11}$ Department of Neurology, Mayo Clinic, 4500 San Pablo Road, Jacksonville, FL 32224, USA. ${ }^{12}$ Department of Neurology, Drexel University College of Medicine, 2900 W Queen Ln, Philadelphia, PA 19129, USA. ${ }^{13}$ Department of Neurology, Mayo Clinic, 5777 E Mayo Blvd, Phoenix, AZ 85054, USA. ${ }^{14}$ Department of Neurology, Mayo Clinic, 1216 2nd St SW, Rochester, MN 55902, USA ${ }^{15}$ Department of Pathology and Laboratory Medicine, University of British Columbia, 2329W Mall, Vancouver, BC V6T 1Z4, Canada.

Received: 7 August 2014 Accepted: 29 August 2014 Published: 20 September 2014

\section{References}

1. Lomen-Hoerth C, Anderson T, Miller B: The overlap of amyotrophic lateral sclerosis and frontotemporal dementia. Neurology 2002, 59:1077-1079.

2. Lomen-Hoerth C, Murphy J, Langmore S, Kramer JH, Olney RK, Miller B: Are amyotrophic lateral sclerosis patients cognitively normal? Neurology 2003, 60:1094-1097.

3. Giordana MT, Ferrero P, Grifoni S, Pellerino A, Naldi A, Montuschi A: Dementia and cognitive impairment in amyotrophic lateral sclerosis: a review. Neurol Sci 2011, 32:9-16.

4. Phukan J, Pender NP, Hardiman O: Cognitive impairment in amyotrophic lateral sclerosis. Lancet Neurol 2007, 6:994-1003.

5. Neumann M, Sampathu DM, Kwong LK, Truax AC, Micsenyi MC, Chou TT, Bruce J, Schuck T, Grossman M, Clark CM, McCluskey LF, Miller BL, Masliah E, Mackenzie IR, Feldman H, Feiden W, Kretzschmar HA, Trojanowski JQ, Lee VM: Ubiquitinated TDP-43 in frontotemporal lobar degeneration and amyotrophic lateral sclerosis. Science 2006, 314:130-133.

6. Mackenzie IR, Neumann M, Bigio EH, Cairns NJ, Alafuzoff I, Kril J, Kovacs GG, Ghetti B, Halliday G, Holm IE, Ince PG, Kamphorst W, Revesz T, Rozemuller AJ, Kumar-Singh S, Akiyama H, Baborie A, Spina S, Dickson DW, Trojanowski JQ, Mann DM: Nomenclature for neuropathologic subtypes of frontotemporal lobar degeneration: consensus recommendations. Acta Neuropathol 2009, 117:15-18.

7. DeJesus-Hernandez M, Mackenzie IR, Boeve BF, Boxer AL, Baker M, Rutherford NJ, Nicholson AM, Finch NA, Flynn H, Adamson J, Kouri N, Wojtas A, Sengdy P, Hsiung GY, Karydas A, Seeley WW, Josephs KA, Coppola G, Geschwind DH, Wszolek ZK, Feldman H, Knopman DS, Petersen RC, Miller BL, Dickson DW, Boylan KB, Graff-Radford NR, Rademakers R: Expanded GGGGCC hexanucleotide repeat in noncoding region of C9ORF72 causes chromosome 9p-linked FTD and ALS. Neuron 2011, 72:245-256. 
8. Renton AE, Majounie E, Waite A, Simon-Sanchez J, Rollinson S, Gibbs JR, Schymick JC, Laaksovirta H, van Swieten JC, Myllykangas L, Kalimo H, Paetau A, Abramzon Y, Remes AM, Kaganovich A, Scholz SW, Duckworth J, Ding J, Harmer DW, Hernandez DG, Johnson JO, Mok K, Ryten M, Trabzuni D, Guerreiro RJ, Orrell RW, Neal J, Murray A, Pearson J, Jansen IE, et al: A hexanucleotide repeat expansion in C9ORF72 is the cause of chromosome 9p21-linked ALS-FTD. Neuron 2011, 72:257-268.

9. Majounie E, Renton AE, Mok K, Dopper EG, Waite A, Rollinson S, Chio A, Restagno G, Nicolaou N, Simon-Sanchez J, van Swieten JC, Abramzon Y Johnson JO, Sendtner M, Pamphlett R, Orrell RW, Mead S, Sidle KC, Houlden H, Rohrer JD, Morrison KE, Pall H, Talbot K, Ansorge O, Hernandez DG Arepalli S, Sabatelli M, Mora G, Corbo M, Giannini F, et al: Frequency of the C9orf72 hexanucleotide repeat expansion in patients with amyotrophic lateral sclerosis and frontotemporal dementia: a cross-sectional study. Lancet Neurol 2012, 11:323-330.

10. van Blitterswijk M, DeJesus-Hernandez M, Rademakers R: How do C9ORF72 repeat expansions cause amyotrophic lateral sclerosis and frontotemporal dementia: can we learn from other noncoding repeat expansion disorders? Curr Opin Neurol 2012, 25:689-700.

11. van Blitterswijk M, Mullen B, Nicholson AM, Bieniek KF, Heckman MG, Baker MC, Dejesus-Hernandez M, Finch NA, Brown PH, Murray ME, Hsiung GY, Stewart H, Karydas AM, Finger E, Kertesz A, Bigio EH, Weintraub S, Mesulam M, Hatanpaa KJ, White lii CL, Strong MJ, Beach TG, Wszolek ZK, Lippa C, Caselli R, Petrucelli L, Josephs KA, Parisi JE, Knopman DS, Petersen RC, et al: TMEM106B protects C9ORF72 expansion carriers against frontotemporal dementia. Acta Neuropathol 2014, 127:397-406.

12. Gallagher MD, Suh E, Grossman M, Elman L, McCluskey L, Van Swieten JC, Al-Sarraj S, Neumann M, Gelpi E, Ghetti B, Rohrer JD, Halliday G, Van Broeckhoven C, Seilhean D, Shaw PJ, Frosch MP, Alafuzoff I, Antonell A, Bogdanovic N, Brooks W, Cairns NJ, Cooper-Knock J, Cotman C, Cras P, Cruts M, De Deyn PP, DeCarli C, Dobson-Stone C, Engelborghs S, Fox N, et al: TMEM106B is a genetic modifier of frontotemporal lobar degeneration with C9orf72 hexanucleotide repeat expansions. Acta Neuropathol 2014, 127:407-418.

13. van Blitterswijk M, Mullen B, Heckman MG, Baker MC, DeJesus-Hernandez M, Brown PH, Murray ME, Hsiung GY, Stewart $H$, Karydas AM, Finger E, Kertesz A, Bigio EH, Weintraub S, Mesulam M, Hatanpaa KJ, White CL 3rd, Neumann M, Strong MJ, Beach TG, Wszolek ZK, Lippa C, Caselli R, Petrucelli L, Josephs KA, Parisi JE, Knopman DS, Petersen RC, Mackenzie IR, Seeley WW, et al: Ataxin-2 as potential disease modifier in C9ORF72 expansion carriers. Neurobiol Aging 2014, 35:2421. e2413-2427.

14. van Blitterswijk M, DeJesus-Hernandez M, Niemantsverdriet E, Murray ME, Heckman MG, Diehl NN, Brown PH, Baker MC, Finch NA, Bauer PO, Serrano G, Beach TG, Josephs KA, Knopman DS, Petersen RC, Boeve BF, Graff-Radford NR, Boylan KB, Petrucelli L, Dickson DW, Rademakers R: Association between repeat sizes and clinical and pathological characteristics in carriers of C9ORF72 repeat expansions (Xpansize-72): a cross-sectional cohort study. Lancet Neurol 2013, 12:978-988.

15. van Blitterswijk M, Baker MC, Dejesus-Hernandez M, Ghidoni R, Benussi L, Finger E, Hsiung GY, Kelley BJ, Murray ME, Rutherford NJ, Brown PE, Ravenscroft T, Mullen B, Ash PE, Bieniek KF, Hatanpaa KJ, Karydas A, Wood EM, Coppola G, Bigio EH, Lippa C, Strong MJ, Beach TG, Knopman DS, Huey ED, Mesulam M, Bird T, White CL 3rd, Kertesz A, Geschwind DH, et al: C9ORF72 repeat expansions in cases with previously identified pathogenic mutations. Neurology 2013, 81:1332-1341.

16. Wunderley L, Brownhill K, Stefani F, Tabernero L, Woodman P: The molecular basis for selective assembly of the UBAP1-containing endosome-specific ESCRT-I complex. I Cell Sci 2014, 127:663-672.

17. Stefani F, Zhang L, Taylor S, Donovan J, Rollinson S, Doyotte A, Brownhill K, Bennion J, Pickering-Brown S, Woodman P: UBAP1 is a component of an endosome-specific ESCRT-I complex that is essential for MVB sorting. Curr Biol 2011, 21:1245-1250

18. Rollinson S, Rizzu P, Sikkink S, Baker M, Halliwell N, Snowden J, Traynor BJ, Ruano D, Cairns N, Rohrer JD, Mead S, Collinge J, Rossor M, Akay E, Guerreiro R, Rademakers R, Morrison KE, Pastor P, Alonso E, Martinez-Lage P, Graff-Radford N, Neary D, Heutink P, Mann DM, Van Swieten J, Pickering-Brown SM: Ubiquitin associated protein 1 is a risk factor for frontotemporal lobar degeneration. Neurobiol Aging 2009, 30:656-665.

19. Rohrer JD, Mead S, Omar R, Poulter M, Warren JD, Collinge J, Rossor MN: Prion protein (PRNP) genotypes in frontotemporal lobar degeneration syndromes. Ann Neurol 2006, 60:616. author reply 617.
20. Li X, Rowland LP, Mitsumoto H, Przedborski S, Bird TD, Schellenberg GD, Peskind E, Johnson N, Siddique T, Mesulam MM, Weintraub S, Mastrianni JA: Prion protein codon 129 genotype prevalence is altered in primary progressive aphasia. Ann Neurol 2005, 58:858-864.

21. Moreno F, Alzualde A, Camblor PM, Barandiaran M, Van Deerlin VM, Gabilondo A, Marti Masso JF, Lopez de Munain A, Indakoetxea B: Prion protein codon 129 polymorphism modifies age at onset of frontotemporal dementia with the C.709-1G $>$ A progranulin mutation Alzheimer Dis Assoc Disord 2011, 25:93-95.

22. Chiaverini N, De Ley M: Protective effect of metallothionein on oxidative stress-induced DNA damage. Free Radic Res 2010, 44:605-613.

23. Morahan JM, Yu B, Trent RJ, Pamphlett R: Genetic susceptibility to environmental toxicants in ALS. Am J Med Genet B Neuropsychiatr Genet 2007, 144B:885-890.

24. Tokuda E, Okawa E, Watanabe S, Ono S: Overexpression of metallothionein-I, a copper-regulating protein, attenuates intracellular copper dyshomeostasis and extends lifespan in a mouse model of amyotrophic lateral sclerosis caused by mutant superoxide dismutase-1. Hum Mol Genet 2014, 23:1271-1285.

25. Kamel F, Umbach DM, Hu H, Munsat TL, Shefner JM, Taylor JA, Sandler DP: Lead exposure as a risk factor for amyotrophic lateral sclerosis. Neurodegener Dis 2005, 2:195-201.

26. Kamel F, Umbach DM, Lehman TA, Park LP, Munsat TL, Shefner JM, Sandler DP, Hu H, Taylor JA: Amyotrophic lateral sclerosis, lead, and genetic susceptibility: polymorphisms in the delta-aminolevulinic acid dehydratase and vitamin D receptor genes. Environ Health Perspect 2003, 111:1335-1339.

27. Fang $\mathrm{F}$, Kwee LC, Allen KD, Umbach DM, Ye W, Watson M, Keller J, Oddone EZ, Sandler DP, Schmidt S, Kamel F: Association between blood lead and the risk of amyotrophic lateral sclerosis. Am J Epidemiol 2010, 171:1126-1133.

28. Rademakers R, Eriksen JL, Baker M, Robinson T, Ahmed Z, Lincoln SJ, Finch N, Rutherford NJ, Crook RJ, Josephs KA, Boeve BF, Knopman DS, Petersen RC, Parisi JE, Caselli RJ, Wszolek ZK, Uitti RJ, Feldman H, Hutton ML, Mackenzie IR, Graff-Radford NR, Dickson DW: Common variation in the miR-659 binding-site of GRN is a major risk factor for TDP43-positive frontotemporal dementia. Hum Mol Genet 2008, 17:3631-3642.

29. Simon-Sanchez J, Seelaar H, Bochdanovits Z, Deeg DJ, van Swieten JC, Heutink P: Variation at GRN 3'-UTR rs 5848 is not associated with a risk of frontotemporal lobar degeneration in Dutch population. PLOS One 2009, 4:e7494.

30. Galimberti D, Fenoglio C, Cortini F, Serpente M, Venturelli E, Villa C, Clerici F, Marcone A, Benussi L, Ghidoni R, Gallone S, Scalabrini D, Restelli I: Martinelli Boneschi F, Cappa S, Binetti G, Mariani C, Rainero I, Giordana MT, Bresolin N, Scarpini E: GRN variability contributes to sporadic frontotemporal lobar degeneration. J Alzheimers Dis 2010, 19:171-177.

31. Rollinson S, Rohrer JD, van der Zee J, Sleegers K, Mead S, Engelborghs S, Collinge J, De Deyn PP, Mann DM, Van Broeckhoven C, Pickering-Brown SM: No association of PGRN 3'UTR rs5848 in frontotemporal lobar degeneration. Neurobiol Aging 2011, 32:754-755.

32. Pickering-Brown SM, Rollinson S, Du Plessis D, Morrison KE, Varma A, Richardson AM, Neary D, Snowden JS, Mann DM: Frequency and clinical characteristics of progranulin mutation carriers in the Manchester frontotemporal lobar degeneration cohort: comparison with patients with MAPT and no known mutations. Brain 2008, 131:721-731.

33. Winkler GS, Kristjuhan A, Erdjument-Bromage $H$, Tempst P, Svejstrup JQ: Elongator is a histone $\mathrm{H} 3$ and $\mathrm{H} 4$ acetyltransferase important for normal histone acetylation levels in vivo. Proc Natl Acad Sci U S A 2002, 99:3517-3522.

34. Winkler GS, Petrakis TG, Ethelberg S, Tokunaga M, Erdjument-Bromage $H$ Tempst P, Svejstrup JQ: RNA polymerase II elongator holoenzyme is composed of two discrete subcomplexes. J Biol Chem 2001, 276:32743-32749.

35. Belzil W, Bauer PO, Prudencio M, Gendron TF, Stetler $C T$, Yan IK, Pregent $L$, Daughrity L, Baker MC, Rademakers R, Boylan K, Patel TC, Dickson DW, Petrucelli L: Reduced C9orf72 gene expression in C9FTD/ALS is caused by histone trimethylation, an epigenetic event detectable in blood. Acta Neuropathol 2013, 126:895-905.

36. Simpson CL, Lemmens R, Miskiewicz K, Broom WJ, Hansen VK, van Vught PW, Landers JE, Sapp P, Van Den Bosch L, Knight J, Neale BM, Turner MR, Veldink JH, Ophoff RA, Tripathi VB, Beleza A, Shah MN, Proitsi P, Van Hoecke A, Carmeliet P, 
Honvitz HR, Leigh PN, Shaw CE, van den Berg LH, Sham PC, Powell JF, Verstreken P, Brown RH Jr, Robberecht W, Al-Chalabi A: Variants of the elongator protein 3 (ELP3) gene are associated with motor neuron degeneration. Hum Mol Genet 2009, 18:472-481.

37. van Blitterswijk M, Landers JE: RNA processing pathways in amyotrophic lateral sclerosis. Neurogenetics 2010, 11:275-290

38. Rubino E, Vacca A, Govone F, De Martino P, Pinessi L, Rainero I: Apolipoprotein $\mathrm{E}$ polymorphisms in frontotemporal lobar degeneration: a meta-analysis. Alzheimers Dement 2013, 9:706-713.

39. van Es MA, Veldink JH, Saris CG, Blauw HM, van Vught PW, Birve A, Lemmens R, Schelhaas HJ, Groen EJ, Huisman MH, van der Kooi AJ, de Visser M, Dahlberg C, Estrada K, Rivadeneira F, Hofman A, Zwarts MJ, van Doormaal PT, Rujescu D, Strengman E, Giegling I, Muglia P, Tomik B, Slowik A, Uitterlinden AG, Hendrich C, Waibel S, Meyer T, Ludolph AC, Glass JD, et al: Genome-wide association study identifies 19p13.3 (UNC13A) and 9 p21.2 as susceptibility loci for sporadic amyotrophic lateral sclerosis. Nat Genet 2009, 41:1083-1087.

40. Diekstra FP, Saris CG, van Rheenen W, Franke L, Jansen RC, van Es MA, van Vught PW, Blauw HM, Groen EJ, Horvath S, Estrada K, Rivadeneira F, Hofman A, Uitterlinden AG, Robberecht W, Andersen PM, Melki J, Meininger V, Hardiman O, Landers JE, Brown RH Jr, Shatunov A, Shaw CE, Leigh PN, Al-Chalabi A, Ophoff RA, van den Berg LH, Veldink JH: Mapping of gene expression reveals CYP27A1 as a susceptibility gene for sporadic ALS. PLoS One 2012, 7:e35333.

41. Augustin I, Rosenmund C, Sudhof TC, Brose N: Munc13-1 is essential for fusion competence of glutamatergic synaptic vesicles. Nature 1999, 400:457-461.

42. Glickman ME, Rao SR, Schultz MR: False discovery rate control is a recommended alternative to Bonferroni-type adjustments in health studies. J Clin Epidemiol 2014, 67:850-857.

43. Dudoit S, van der Laan MJ, Pollard KS: Multiple testing. Part I. Single-step procedures for control of general type I error rates. Stat Appl Genet Mol Biol 2004, 3:Article13.

44. Benjamini $Y$, Hochberg $Y$ : Controlling the false discovery rate: a practical and powerful approach to multiple testing. J R Stat Soc B 1995, 57:289-300

doi:10.1186/1750-1326-9-38

Cite this article as: van Blitterswijk et al: Genetic modifiers in carriers of repeat expansions in the C9ORF72 gene. Molecular Neurodegeneration 2014 9:38.

\section{Submit your next manuscript to BioMed Central and take full advantage of:}

- Convenient online submission

- Thorough peer review

- No space constraints or color figure charges

- Immediate publication on acceptance

- Inclusion in PubMed, CAS, Scopus and Google Scholar

- Research which is freely available for redistribution 